\title{
The Use of Indwelling Pleural Catheters for the Management of Malignant Pleural Effusion - Direct Costs in a Dutch Hospital
}

\author{
Rogier C. Boshuizen Suzanne Onderwater Sjaak J.A. Burgers \\ Michel M. van den Heuvel \\ Department of Thoracic Oncology, The Netherlands Cancer Institute, Amsterdam, The Netherlands
}

For editorial comment see p. 181

\section{Key Words \\ Costs · Indwelling pleural catheter · Malignant pleural effusion · Pleurodesis}

\begin{abstract}
Background: Indwelling pleural catheters (IPCs) are increasingly used in the treatment of malignant pleural effusion (MPE). In general, these catheters have been reported to manage MPE efficiently. Unfortunately, insurance companies in the Netherlands do not reimburse these catheters in either first-line treatment or following failed talc pleurodesis. Objectives: Investigation of direct costs of IPC placement. Methods: Retrospective analysis of a prospectively collected database. Direct costs for both catheters and vacuum bottles were calculated. Indicators for indirect costs such as adverse events and complications and the need for additional home care for drainage were registered. Results: Mean costs for IPC amounted to EUR 2,173 and were different between tumor types - mesothelioma: EUR 4,028, breast: EUR 2,204, lung: EUR 1,146 and other: EUR 1,841; $p=0.017$. Four patients were admitted to hospital for treatment of complications. Mean costs for IPC placement was similar when inserted as frontline treatment and after failed pleurodesis. Approximately $75 \%$ of patients did not need any help from
\end{abstract}

specialized home care. Conclusion: Direct costs for IPC placement turn out to be acceptable when compared with estimated hospitalization costs for pleurodesis treatment. Randomized controlled trials have to be performed to compare the cost-effectiveness of IPCs compared to pleurodesis.

Copyright $\odot 2013$ S. Karger AG, Basel

\section{Background}

Malignant pleural effusion (MPE) is a common complication of malignancy. The prognosis is poor with patients having a median survival of 3-12 months [1]. MPE can cause significant shortness of breath, and therefore treatment focuses mainly on palliation. In general, recurrent MPE is treated with the instillation of sterile talc into the pleural space, according to current guidelines [2-5]. Mean hospitalization duration for pleurodesis is $4-8$ days [6]. The percentage success rate of pleurodesis is approximately $80 \%$, according to the guidelines of the British Thoracic Society [1]. This percentage decreases over time [3] and depends on definition [7,8].

When talc pleurodesis fails, insertion of an indwelling pleural catheter (IPC) can be considered [9]. An IPC is a subcutaneously tunneled catheter, which enables patients

\section{KARGER}

E-Mail karger@karger.com

www.karger.com/res
(C) 2013 S. Karger AG, Basel

0025-7931/13/0863-0224\$38.00/0
R.C. Boshuizen

Department of Thoracic Oncology, The Netherlands Cancer Institute Plesmanlaan 121

NL-1066 CX Amsterdam (The Netherlands)

E-Mail r.boshuizen@nki.nl 
and their caregivers to perform drainages at home. Alternative treatment options for recurrent pleural effusion range from the very invasive (pleurectomy) to no intervention (abstination). More frequently, a second pleurodesis or repeat therapeutic drainages are undertaken.

Recently, results of 2 randomized controlled trials comparing the effectiveness of IPC to talc pleurodesis as frontline treatment for MPE were published $[10,11]$. In the Second Therapeutic Intervention in Malignant Effusion (TIME2) study, patients reported dyspnea equally in both treatment arms, 6 weeks after randomization. Incidences of serious adverse events were also comparable. Patients who were randomized to talc pleurodesis had a longer hospital stay (median 4 vs. 0 days, $\mathrm{p}<0.001$ ) [10]. This difference was also seen when patients chose either IPC or talc pleurodesis [12]. Patients who had been treated with an IPC would choose it again [13].

In 2000, Putnam et al. [14] demonstrated that total hospital charges were reduced when patients were treated with an IPC instead of doxycycline pleurodesis. An IPC rather than talc pleurodesis was shown to be most costeffective when patients survived less than 6 weeks [15]. Two years later, repeat thoracenteses, IPC and pleurodesis were compared in another cost-effective analysis. IPC was considered most cost-effective when patient survival was 3 months [16].

IPCs appear cost-effective in managing MPE. Unfortunately, in the Netherlands, reimbursement is organized in such a way that the costs of vacuum bottles (direct costs) have to be paid by the respiratory department of the hospital. This might prevent optimal use of IPCs. In this article, we describe the direct costs of IPCs in a Dutch hospital.

\section{Materials and Methods}

Indwelling Pleural Catheter

Between September 2009 and April 2012, 65 IPCs were inserted for symptomatic MPE in the Netherlands Cancer Institute. The insertion technique has been described previously [17].

Database

Patient-related and intervention-related details such as age, gender, past medical history and systemic antitumor treatment were recorded in a prospective database. Use of a prospective database was approved by the Medical Ethical Committee of the Netherlands Cancer Institute. All interventions for MPEs, motivation for IPC insertion and complications were documented. It was also recorded who performed the domiciliary drainages: the patient, their family or nurses. Vacuum bottles were ordered by the respiratory department. These data were compared to distribution data provided by the supplier.

IPCs for the Management of MPE
Direct Costs

Since 2009, costs for an IPC insertion set are EUR 255 (excl. tax), EUR 310 (excl. tax) per 5 vacuum bottles $(600 \mathrm{ml})$ and EUR 195 (excl. tax) per 5 peritoneal drainage bags. No other costs had to be made to perform drainages at home. Direct costs were calculated using the costs of insertion sets and vacuum bottles or peritoneal drainage bags.

\section{Statistics}

Groups were compared using the ANOVA test. p values $<0.05$ were considered to be significant. In general, mean costs were displayed representing the daily practice. Median values were used for survival times. Unless otherwise mentioned, variables were reported per inserted catheter and not per patient.

\section{Results}

\section{Patient Characteristics}

Sixty patients underwent 65 IPC insertions. Eleven patients were treated by their referring pulmonologist elsewhere. These patients were excluded from analysis, due to the absence of proper follow-up data. In 4 patients, an IPC was inserted for reasons other than MPE (infection following an extrapleural pneumonectomy, radiation pleuritis, yellow nail syndrome and terminal heart failure) and were also not included in this overview. Five patients underwent bilateral IPC insertion. In total, 50 IPCs in 45 patients were used in this analysis (table 1). IPC insertion was performed due to failed ipsilateral pleurodesis $(n=20)$. Thirty patients had an IPC placement as a frontline treatment: due to failed contralateral pleurodesis $(\mathrm{n}=10)$ or upon explicit demand by a medical oncologist or the patient $(\mathrm{n}=8)$. Twelve patients were treated with an IPC as frontline treatment in the trial.

Four patients also had an IPC in situ for ascites drainage. Four patients underwent pericardial drainages for malignant pericardial effusion. During this analysis, 2 patients were still alive at 301 and 265 days after IPC insertion; their IPCs had been removed 183 and 94 days after placement, respectively. Overall survival was 51 days (95\% CI 63-150) and did not differ between patients with an IPC as frontline treatment $(\mathrm{n}=30)$ (67 days, 95\% CI 62-129) and patients who had previously undergone an ipsilateral pleurodesis $(\mathrm{n}=20)$ (39 days, 95\% CI 24$221 ; \mathrm{p}=0.551)$. Patients suffering from mesothelioma had the longest median overall survival (time between IPC placement and death) of 294 days, followed by patients suffering from breast cancer (58 days), lung cancer (45 days) and patients with other tumors (44 days, $\mathrm{p}=$ $0.002)$. 
Table 1. Patient characteristics

\begin{tabular}{|c|c|c|}
\hline & $\begin{array}{l}\text { IPCs } \\
(\mathrm{n}=50)\end{array}$ & $\begin{array}{l}\text { Patients }^{1} \\
(\mathrm{n}=45)\end{array}$ \\
\hline \multicolumn{3}{|l|}{ Age, years } \\
\hline Mean & & 57 \\
\hline Range & & $30-83$ \\
\hline \multicolumn{3}{|l|}{ Side } \\
\hline Left & 27 & \\
\hline Right & 23 & \\
\hline \multicolumn{3}{|l|}{ Gender } \\
\hline Female & & 26 \\
\hline Male & & 19 \\
\hline \multicolumn{3}{|c|}{ Previous admissions for pleurodesis } \\
\hline No & 30 & \\
\hline Yes, talc instillation & 10 & \\
\hline Yes, no talc instillation & 10 & \\
\hline \multicolumn{3}{|l|}{ Tumor type } \\
\hline Breast & 15 & 13 \\
\hline Lung & 8 & 8 \\
\hline Mesothelioma & 7 & 6 \\
\hline Gastrointestinal & 5 & 4 \\
\hline Urogenital & 5 & 5 \\
\hline Ovarian & 4 & 4 \\
\hline Other ${ }^{2}$ & 6 & 5 \\
\hline
\end{tabular}

\footnotetext{
${ }^{1}$ Five patients had bilateral IPCs.

${ }^{2}$ Other tumors: 2 patients suffered from a head-and-neck malignancy, 2 from an adenocarcinoma of unknown primary and 1 had bilateral pleural effusion caused by melanoma.
}

Table 2. Complications following IPC placement

\begin{tabular}{lll}
\hline Complication & Intervention & $\begin{array}{l}\text { IPCs } \\
(\mathrm{n}=50)\end{array}$ \\
\hline Major complications & & 5 \\
Empyema & intravenous antibiotics & 2 \\
Dislocation & replacement & 1 \\
Mechanical & replacement & 1 \\
Tract metastasis & radiotherapy & 1 \\
Minor complications & & 9 \\
Loculations & drain removal & 3 \\
Superficial skin infection & oral antibiotics & 2 \\
Mechanical & reparation & 1 \\
Pain during drainage & peritoneal drainage bags & 1 \\
Leakage & 'wait and see' & 1 \\
Pneumothorax after & & 1 \\
$\quad$ insertion & extra drain & 36 \\
No complications & not applicable & 1 \\
\hline
\end{tabular}

In approximately $75 \%$ of cases, there were no complications.

\section{Pleural Intervention prior to IPC Insertion}

Prior to IPC insertion, patients underwent 2.4 ipsilateral therapeutic thoracenteses (median 2, range 0-8). Twenty patients had previously been admitted to the hospital for ipsilateral pleurodesis and in 10 patients, no talc was instilled due to insufficient lung expansion following drainage. These 20 patients had a mean hospitalization time of 6.1 days (median 6, range 2-19). Median time from IPC insertion to death was similar for patients with and without talc instillation ( 43 vs. 35 days; $p=0.621$ )

\section{Pleural Interventions following IPC Insertion}

No patient required a reintervention for MPE management following IPC insertion. Nine IPCs were removed, mostly due to decreased fluid production.

\section{Direct Costs of the IPC}

Direct cost per IPC amounted to EUR 2,137 (median EUR 1,495, range EUR 379-8,315). IPC costs were not different when comparing first-line-inserted IPCs with IPCs inserted following ipsilateral pleurodesis (EUR 1,888 vs. 2,512, $\mathrm{p}=0.259$ ). Costs for the use of an IPC were higher when patients also had an indwelling peritoneal catheter (EUR 4,518 vs. 1,$931 ; \mathrm{p}=0.008$; bottles or bags for peritoneal uses have been excluded from the analysis). Pericardial effusion did not influence the direct costs for using an IPC. IPCs incurred the lowest costs when inserted in patients suffering from lung carcinoma (EUR 1,146 ) in contrast to mesothelioma (EUR 4,028). Patients suffering from breast cancer and other tumors had IPC costs of between EUR 2,204 and 1,841 ( $\mathrm{p}=0.017)$. Using an IPC for a period $<6$ weeks significantly lowered costs compared to longer use (EUR 1,100 vs. 2,273; $\mathrm{p}=0.002$ ). Patients who were treated with systemic antitumor therapy $(\mathrm{n}=24)$ had a better median survival (104 vs. 39 days; $\mathrm{p}=0.00714)$ and IPC costs were therefore higher (EUR 2,916 vs. 1,$481 ; \mathrm{p}=0.008$ ). Daily costs (total costs divided by drainage duration) did not differ between tumor types (lung EUR: 36.9, other: EUR 40.5, mesothelioma: EUR 45.9 and breast: EUR 50.7; $\mathrm{p}=0.842$ )

\section{Complications}

Approximately $75 \%$ of IPC insertions were without complications (table 2). Four patients were admitted for $1,3,12$ and 14 days with painful drainage, pneumothorax and empyema (2 admissions), respectively. One empyema developed while the patient was receiving antitumor therapy ( 1 out of 24 patients). One patient out of 26 who did not receive any systemic antitumor treatment developed an empyema. 
One IPC had to be reinserted following dislocation during a coughing episode and one was damaged during removal of stitches and had to be replaced. One patient had a leaking drainage valve, which was easily repaired. One patient developed a tract-metastasis 11 months after IPC insertion, and was successfully palliated with radiotherapy.

\section{Drainages}

Most patients did not require the help of nurses with drainages. Four patients performed the drainages themselves and 17 (20 IPCs) performed the drainages with the help of their family. The drainages of 12 patients (24\%) were performed by family alone. Twelve patients (14 IPCs, 28\%) had the drainages performed by home-visiting nurses or during hospital visits.

\section{Discussion}

In this overview, we showed that the mean direct costs per IPC amounted to EUR 2,137. With the current reimbursement structure in the Netherlands, these costs have to be paid by the hospital.

The mean price of one hospitalization day in the Netherlands in 2010 was EUR 1,400 [18]. This leads to EUR 5,600-11,200 for a 4- to 8-day hospital stay for pleurodesis. These prices vary between hospitals and are not transparent due to closed negotiations between hospitals and insurance companies. Compared to these figures, costs for the use of an IPC are acceptable, especially considering the limited success rate of talc pleurodesis.

In this overview, all material costs are summed, but the total costs for using an IPC also include costs of complications, reinterventions and daily care during the drainages. None of the patients required reinterventions related to recurrent ipsilateral MPE. The complication rate was comparable to previously reported studies $[19,20]$ and 4 patients needed complication-related hospitalization. Two patients needed IPC replacement. Replacement of a defective valve has previously been described [21]. One patient developed a tract metastasis. This is a rare complication, with a higher incidence rate in mesothelioma [22]. The benefit of prophylactic radiotherapy for prevention of tract metastasis in mesothelioma is debatable [23]. National guidelines for mesothelioma treatment do not recommend prophylactic radiotherapy [24]. These and other costs (e.g. radiology or theatre) are not included, since they do not contribute to the hospital expenses.

IPCs for the Management of MPE
Other indirect costs (e.g. loss of income, travel costs and home care visits) are also not included in this overview. The vast majority of patients no longer worked due to advanced disease. Travel costs for patients using an IPC should be less than the cost of repeat thoracentesis. Costs for home care were also excluded, as it remains unclear whether these patients needed to be visited by nurses when they did not have an IPC. However, the percentage of patients in whom drainages were performed by home care was low.

In contrast to two cost-effective analyses, we chose to avoid assumptions about alternative treatments $[15,16]$. Small differences in assumptions can have significant consequences for cost-effectiveness [25]. In our opinion, pleurodesis success rates of $80 \%$ in these analyses are too optimistic as intention-to-treat analysis has not been taken into consideration. According to our data, $32-71 \%$ is a more realistic percentage $[7,8]$. It was assumed that patients required home care three times a week [15]. Our patient selection might have been biased by their ability to perform drainages themselves, but the majority did not need professional help. Furthermore, we realize that drainage without professional help might differ from that in other centers.

The costs of vacuum bottles are a major factor in the total costs of IPC usage. In an Egyptian hospital, the safety of reusable Surgivac pumps was investigated [26]. A vacuum was created manually and caregivers had to clean the pump system after drainage. Complication rates were acceptable with substantially lower costs. This will hopefully not be necessary in the Netherlands as patients and family are now able to perform drainages themselves. In some patients, the usage of (peritoneal) drainage bags could also be an alternative to the (more expensive) vacuum bottles. At this time, at least two brands of IPCs: PleurX (Denver-Carefusion) and Rocket (Rocket Medical) are available. Competition might reduce vacuum bottle prices.

\section{Conclusion}

To the best of our knowledge, this is the first study showing the direct costs of IPC treatment. Costs are dependent on tumor type and survival time. No differences in costs were seen when IPC was used as frontline treatment or following failed pleurodesis. Comparing these material costs to estimated costs for pleurodesis, IPC treatment seems reasonably priced. Complication rates appear acceptable. 


\section{Acknowledgement}

The Netherlands Cancer Institute received a research grant funding from Nuts-OHRA and the Dutch Cancer Society for the Treatment of Malignant Pleural Effusion. We acknowledge Marieke Groot Obbink for collecting data and the supplier of the vacuum bottles for providing distribution data.

\section{Financial Disclosure and Conflicts of Interest}

None of the authors reported any conflicting interests.

\section{References}

1 Roberts ME, Neville E, Berrisford RG, et al: Management of a malignant pleural effusion: British Thoracic Society Pleural Disease Guideline 2010. Thorax 2010;65(suppl 2): ii32-ii40.

2 Chen H, Brahmer J: Management of malignant pleural effusion. Curr Oncol Rep 2008; 10:287-293.

3 Dresler CM, Olak J, Herndon JE, et al: Phase III intergroup study of talc poudrage vs talc slurry sclerosis for malignant pleural effusion. Chest 2005;127:909-915.

- 4 Haddad FJ, Younes RN, Gross JL, et al: Pleurodesis in patients with malignant pleural effusions: talc slurry or bleomycin? Results of a prospective randomized trial. World J Surg 2004;28:749-753.

5 Shaw P, Agarwal R: Pleurodesis for malignant pleural effusions. Cochrane Database Syst Rev 2004:CD002916.

6 Goodman A, Davies CW: Efficacy of shortterm versus long-term chest tube drainage following talc slurry pleurodesis in patients with malignant pleural effusions: a randomised trial. Lung Cancer 2006;54:51-55.

-7 Boshuizen RC, Vincent AD, Kunst PW, et al: Talc instillation consensus AIDS differentiating successful from unsuccessful pleurodesis: a survey on the interpretation of pleural approximation after chest tube placement. Respiration 2013;85:85-86.

8 Burgers JA, Kunst PW, Koolen MG, et al: Pleural drainage and pleurodesis: implementation of guidelines in four hospitals. Eur Respir J 2008;32:1321-1327. $\checkmark 9$ Pien GW, Gant MJ, Washam CL, et al: Use of an implantable pleural catheter for trapped lung syndrome in patients with malignant pleural effusion. Chest 2001;119:1641-1646.

10 Davies HE, Mishra EK, Kahan BC, et al: Effect of an indwelling pleural catheter vs chest tube and talc pleurodesis for relieving dyspnea in patients with malignant pleural effusion: the TIME2 randomized controlled trial. JAMA 2012;307:2383-2389.

11 Demmy TL, Gu L, Burkhalter JE, et al: Optimal management of malignant pleural effusions (results of CALGB 30102). J Natl Compr Canc Netw 2012;10:975-982.

12 Fysh ET, Waterer GW, Kendall P, et al: Indwelling pleural catheters reduce inpatient days over pleurodesis for malignant pleural effusion. Chest 2012;142:394-400.

13 Sabur NF, Chee A, Stather DR, et al: The impact of tunneled pleural catheters on the quality of life of patients with malignant pleural effusions. Respiration 2013;85:36-42.

14 Putnam JB Jr, Walsh GL, Swisher SG, et al: Outpatient management of malignant pleural effusion by a chronic indwelling pleural catheter. Ann Thorac Surg 2000;69:369-375.

15 Olden AM, Holloway R: Treatment of malignant pleural effusion: PleuRx catheter or talc pleurodesis? A cost-effectiveness analysis. J Palliat Med 2010;13:59-65.

16 Puri V, Pyrdeck TL, Crabtree TD, et al: Treatment of malignant pleural effusion: a cost-effectiveness analysis. Ann Thorac Surg 2012; 94:374-379.
17 Burgers JA, Olijve A, Baas P: Ervaringen met een verblijfsdrain in de thorax bij 25 patiënten met pleuritis carcinomatosa. Ned Tijdschr Geneeskd 2006;150:1618-1623.

18 Financial Statistics. 2013.

19 Pollak JS: Malignant pleural effusions: treatment with tunneled long-term drainage catheters. Curr Opin Pulm Med 2002;8:302-307.

20 Tremblay A, Michaud G: Single-center experience with 250 tunnelled pleural catheter insertions for malignant pleural effusion. Chest 2006;129:362-368

21 Bower C, Mahmood K: Re: Noninvasive repair of broken tunneled pleural catheters. J Vasc Interv Radiol 2011;22:255-256.

22 Janes SM, Rahman NM, Davies RJ, et al: Catheter-tract metastases associated with chronic indwelling pleural catheters. Chest 2007;131: 1232-1234.

23 Lee C, Bayman N, Swindell R, et al: Prophylactic radiotherapy to intervention sites in mesothelioma: a systematic review and survey of UK practice. Lung Cancer 2009;66:150156.

24 Burgers JA, Schlósser NJJ, Aertz JGVV, et al: Richtlijn diagnostiek en behandeling van het mesothelioom. Amsterdam, 2011.

25 van den Berg M, Hamberg-van Reenen HH, Schoemaker CG: Cost-effectiveness: Euros per QALY is not enough. Ned Tijdschr Geneeskd 2012;156:A3817.

26 Al-Halfawy A, Light R: Safety and efficacy of using a surgivac pump for the drainage of chronic indwelling pleural catheters in malignant pleural effusions. Respirology 2008; 13 : 461-464. 